\title{
Analysis of drug resistance mutation and signature pattern in the archived DNA of HIV-1 infected North Indian patients
}

\section{Sushanta Kumar Barik}

National JALMA Institute of Leprosy and other Mycobacterial Diseases

Keshar Kunja Mohanty ( $\nabla$ keshar63@yahoo.com )

National JALMA Institute for Leprsoy and Other Mycobacterial Diseases https://orcid.org/0000-00017527-4864

\section{Partha Sarathi Mohanty}

National JALMA Institute of Leprosy and other Mycobacterial Diseases

\section{Luke Elizabeth Hanna}

National Institute of Research in Tuberculosis

\section{Ramesh Karunaianantham}

National Institute of Research in Tuberculosis

\section{Srikanth Prasad Tripathy}

National Institute of Research in Tuberculosis

\section{Rekha Tandon}

National Institute of Research in Tuberculosis

\section{Tej Pal Singh}

SN Medical College

\section{Srikanta Jena}

Ravenshaw University

\section{Research article}

Keywords: Human immunodeficiency virus (HIV), Acquire immunodeficiency syndrome (AIDS), Antiretroviral therapy (ART), protease (PR), reverse transcriptase (RT)

Posted Date: May 10th, 2020

DOI: https://doi.org/10.21203/rs.3.rs-26773/v1

License: (c) (1) This work is licensed under a Creative Commons Attribution 4.0 International License. Read Full License 


\section{Abstract}

Background Characterization of drug resistance mutations and signature pattern in the archived DNA of HIV-1 infected North Indian patients.

Methods Blood samples were collected from 9 patients enrolled in ART Centre, S.N. Medical College, Agra, North India from 1 year to $=<7$ years. DNA was isolated and amplified for protease and reverse transcriptase genes using nested primers from WHO dried blood spot protocol 2010. The polymerase chain reaction products were sequenced and drug resistance mutation patterns were analysed using the HIV drug resistance database, Stanford University, USA. Various computational tools and websites like Stanford HIV drug resistance database, Viral epidemiological signature pattern analysis (VESPA), Hypermutation, SNAP version 2.1.1, Entropy were utilized for analysis of the sequence data.

Results This study enables an analysis of archived DNA samples in patients having lower viral load and where the situation of HIV RNA isolation was negligible. Lamivudine associated drug-resistant mutations such as M184V/M184I, nevirapine associated mutations Y181C and H221Y and efavirenz associated mutations M230I were observed in two patients. No mutations were observed in the remaining seven patients. The signature pattern analysis of 9 protease and reverse transcriptase genes identified the conservation of amino acid sequences as compared to the reference sequence. The signature pattern of nucleotide substitution (synonymous to non-synonymous ratio) of the protease gene was 5.02 and the reverse transcriptase gene was 7.01. No hyper mutation was observed in the protease and reverse transcriptase gene of the archived DNA.

Conclusions The analysis of the drug resistance mutation in the protease and reverse transcriptase gene of the archived DNA of HIV-1 subtype $C$ infected patients over 1 to $=<7$ years of first-line ART may be helpful in the treatment guideline in North Indian patients. A few signature amino acids were persisted in the reverse transcriptase and protease gene of similar HIV-1 subtype $C$ infected patients over 1 to $=<$ 7 years of first line ART in comparison to the reference sequence. This archived DNA drug resistance mutation testing could be an important tool when RNA testing becomes unsuccessful.

\section{Background}

Epidemiological analysis of human immune-deficiency virus (HIV) infection and acquired immunodeficiency syndrome (AIDS) in the major cities of India are not well known. It is essential to characterize the epidemiological features of several HIV subtypes circulating in Agra, North India. The circulation of $H I V-1$ subtypes and the amino acid changes in the replication units would play a major role in the fitness of the virus. Since 1986, the HIV epidemic has spread in different cities of the country. HIV-1 subtype $C$ is predominant while the subtype $A, B, A / C, B / C$ mosaic viruses are also being reported from different regions of the country [1].Every year the IAS-USA drug resistance mutation group is reviewing the drug resistance-associated mutations, drug classes and approved new drugs for anti-retroviral therapy users. The list of mutations provided by the expert groups highlighted the pattern of mutations with drug panels 
[2]. The full-length HIV-1 proviral genome was characterized [3]. HIV proviral DNA drug resistance mutations were reported from the community treatment program [4]. Drug resistance mutation analysis of archived DNA could help in choosing the proper regimen at a low level or suppressed viremia patients [5]. Viral Epidemiological Signature Pattern Analysis (VESPA) was used to determine the signature pattern of amino acids and nucleic acid sequences. This VESPA method was first applied to the HIV-1 signature patterns for the $\mathrm{C} 2-\mathrm{V} 3$ region sequences obtained from individuals in the Florida dentist study [6].APOBEC (apolipoprotein B mRNA editing enzyme, catalytic polypeptide-like) proteins act like innate immunity in the vertebrate system which inhibits retroviruses by delaminating the cytosine residues in the nascent retroviral cDNA. The human immunodeficiency virus encodes the Vif protein (Viral infectivity factor) that degrades the $A P O B E C$ protein to collapse the immune system [7]. Shannon entropy was used to measure the HIV-1 protein sequence diversity. High entropy is a general indication of high diversity. The wide range of entropy was observed in variant motifs of different sequences [8].

Therefore, the analysis of the drug resistance mutations, the signature pattern of amino acids, hyper mutation, and variations in the sequences of protease and reverse transcriptase gene in archived DNA would be an essential tool to identify low viral load in HIV patient. Thus, the patients with low level viremia and having drug resistance mutations have higher chances of failure of therapy. Thus, in the present study, an attempt has been made to isolate the archived DNA for the detection of drug resistance mutations, VESPA analysis, hyper mutation analysis, Shannon entropy calculation, etc. that may help to check the efficacy of the regimen and molecular organization of the virus.

\section{Methods}

\section{Study design and participants}

The patients included in this study were enrolled for first-line ART for the period between December 2009 to November 2016 in the ART Centre, S.N. Medical College, Agra, North India. A total of 9 patients was included in this study having CD4 counts oscillated around $<350 /$ cubic $\mathrm{mm}$ during the period of treatment. A patient information leaflet was used for the collection of socio-demographic and clinical profile [9]. Informed consent was taken from all patients.

\section{Ethics approval}

This study protocol was approved by the institutional ethics committee as per the guidelines directed by the Indian Council of Medical Research [10].

\section{Viral load}

For each patient $10 \mathrm{ml}$ of blood sample was collected and viral load estimation was done. Plasma viral load was done by using the Abbott automated m2000rt instrument. The archived DNA of the 9 targets not detected samples was considered for genotyping. These patients were in different phases of ART between 1 year to $=<7$ years. 


\section{Genotyping}

Genotyping was performed by using the primers of WHO dried blood spot protocol 2010. The details of the polymerase chain reaction and sequencing primers as well as amplification conditions of two step polymerase chain reaction ( 1 st round and 2 nd round) are given in the supplementary tables $A 1, A 2$ and A3.

(i) DNA extraction, PCR and Sequencing: DNA was extracted from the whole blood of nine patients using the QIAamp DNA blood mini kit (Qiagen Inc. Germany) according to the manufacturer's advice. The amplification conditions and primer sequences were taken from the WHO dried blood spot protocol 2010 [11]. The extracted DNA samples were amplified in two consecutive rounds in nested PCR. The $835 \mathrm{bp}$ protease and $776 \mathrm{bp}$ reverse transcriptase gene fragment were amplified and sequenced.

(ii) PCR product purification and sequencing: Second-round PCR products were purified by using the Macherey-Nagel Kit. Purified PCR products were sequenced directly using the set of primers in a $3031 \mathrm{XL}$ big dye terminator sequencer (Applied biosystem, USA).

(iii) Drug resistance mutation analysis: Genotyping was performed and the drug resistance mutations were analysed through HIV drug resistance database, Stanford University, USA. (http://hivdb.stanford.edu/pages/algs/sierra_sequence.html).

\section{Gene Bank accession number}

All the sequences were submitted to Gene Bank and accession number was given (MH503757 to MH503765).

\section{Bioinformatics analysis}

The nucleotide sequences of the protease (PR) and reverse transcriptase $(R T)$ gene were aligned by multiple sequence alignment tools (www.ebi.ac.uk/tools/mas). The nucleotide sequences were converted into amino acid sequences by EMBOSS Tran seq (www.ebi.ac.uk/Tools/st/emboss_transeq). The complete protease gene length (position:1nt to 297nt) and the RT gene length (position: 310nt to 988nt) were taken for signature pattern analysis, hypermutation analysis, selection pressure analysis and Shannon entropy calculation. The VESPA (Viral Epidemiology Signature Pattern Analysis) program was used for comparison of amino acid sequences in the PR and RT gene for archived DNA.The VESPA program is available in the HIV Databases (https://www.hiv.lanl.gov). The reference sequence of protease gene and reverse transcriptase gene is being taken the HIV-1 subtype $C$ (Gene bank accession number: AB023804) and 9 archived DNA sequences taken as a query sequence in VESPA analysis. The selection pressure analysis of $P R$ and $R T$ genes was performed using the SNAP version 2.1.1 (synonymous nonsynonymous analysis program tool (www.hivlanl.gov).

The hypermutation analysis of $P R$ and $R T$ genes of archived DNA was performed through this website: (www.hiv.lanl.gov/HYPERMUT/hypermut). Shannon Entropy at each amino acid position of $P R$ and $R T$ 
gene of archived DNA was calculated using the Shannon Entropy online tool at the Los Alamos National Laboratory HIV Sequence Database

(https://www.hiv.lanl.gov/content/sequence/ENTROPY/entropy_option.html).

\section{Results}

Drug resistance mutations M184V and M184I (lamivudine), Y181C \& H221Y (nevirapine and efavirenz) and \& M230I (efavirenz) in the HIV-1 subtype C reverse transcriptase gene of archived DNA were observed in two patients. No mutations were detected in the reverse transcriptase and protease genes in remaining seven archived DNA.

The details of regimen profiles, viral load and drug resistance mutations of protease and reverse transcriptase genes are given in the Table-1.

Table 1

Details of Regimen, Viral load and Mutation Profile

\begin{tabular}{|c|c|c|c|c|c|c|}
\hline \multirow{2}{*}{$\begin{array}{l}\text { Sample } \\
\text { Sl. No } \\
1\end{array}$} & \multirow{2}{*}{$\begin{array}{l}\text { HIV-1 } \\
\text { Subtypes } \\
\text { C }\end{array}$} & \multirow{2}{*}{$\begin{array}{l}\text { Mutation in } \\
\text { Protease gene } \\
\text { None }\end{array}$} & \multicolumn{2}{|c|}{$\begin{array}{l}\text { Mutation in Reverse } \\
\text { transcriptase gene }\end{array}$} & \multirow{2}{*}{$\begin{array}{l}\text { Regimens } \\
\text { ZLN, TLE }\end{array}$} & \multirow{2}{*}{$\begin{array}{l}\text { Viral load }(<40 \\
\text { copies } / \mathrm{ml})\end{array}$} \\
\hline & & & None & None & & \\
\hline 2 & C & None & None & None & TLE & $\begin{array}{l}\text { Target not } \\
\text { detected }\end{array}$ \\
\hline 3 & C & None & None & None & $\begin{array}{l}\text { SLN, TLN, } \\
\text { ZLN, TLE }\end{array}$ & $\begin{array}{l}\text { Target not } \\
\text { detected }\end{array}$ \\
\hline 4 & C & None & None & None & ZLN, ZLE & $\begin{array}{l}\text { Target not } \\
\text { detected }\end{array}$ \\
\hline 5 & C & - - - & M184V & $\begin{array}{l}\text { Y181C, } \\
\text { H221Y }\end{array}$ & TLE, TLN & $\begin{array}{l}\text { Target not } \\
\text { detected }\end{array}$ \\
\hline 6 & C & - - & M184I & M230I & ZLE & $\begin{array}{l}\text { Target not } \\
\text { detected }\end{array}$ \\
\hline 7 & C & None & None & None & $\begin{array}{l}\text { ZLN, TLN, } \\
\text { TLE }\end{array}$ & $\begin{array}{l}\text { Target not } \\
\text { detected }\end{array}$ \\
\hline 8 & C & None & None & None & $\begin{array}{l}\text { SLN, ZLN, } \\
\text { TLN, TLE }\end{array}$ & $\begin{array}{l}\text { Target not } \\
\text { detected }\end{array}$ \\
\hline 9 & C & None & None & None & $\begin{array}{l}\text { SLN, ZLN, } \\
\text { TLE, TLN }\end{array}$ & $\begin{array}{l}\text { Target not } \\
\text { detected }\end{array}$ \\
\hline
\end{tabular}

Regimes: $\mathrm{T}=$ Tenofovir, $\mathrm{S}=$ Stavudine, L = Lamivudine, Z = Zidovudine, E = Efavirenz, N = Nevirapine $=$ Genes not sequenced 
The VESPA software was used for amino acid comparison of the 9 archived DNA sequences in subtype C along with the reference sequences of Mochizuki et al., 1999 (Gene bank accession number: AB023804) [12]. This reference sequence was an HIV-1 subtype $C$ isolated from India in the year 1999. To check the atypical amino acid sequences in the archived DNA, the reference sequence (AB023804) was taken for signature pattern study. Full length i:e 99 amino acids for $P R$ gene and 226 amino acids for $R T$ gene were analysed using VESPA. The signature amino acids viz., $36 \mathrm{I}, 82 \mathrm{~V}$ were observed in the $P R$ gene of archived DNA. Signature amino acids 32T (aa position in RT:135T), 39A (aa position in RT :162A), 62T (aa position in $\mathrm{RT}: 165 \mathrm{~T}$ ), 63K (aa position in RT:166K), 108R (aa position in RT:211R), 214A (aa position in RT: $317 \mathrm{~A}$ ) were observed in the $R T$ gene of archived DNA. The signature amino acids are given in the Table-2.

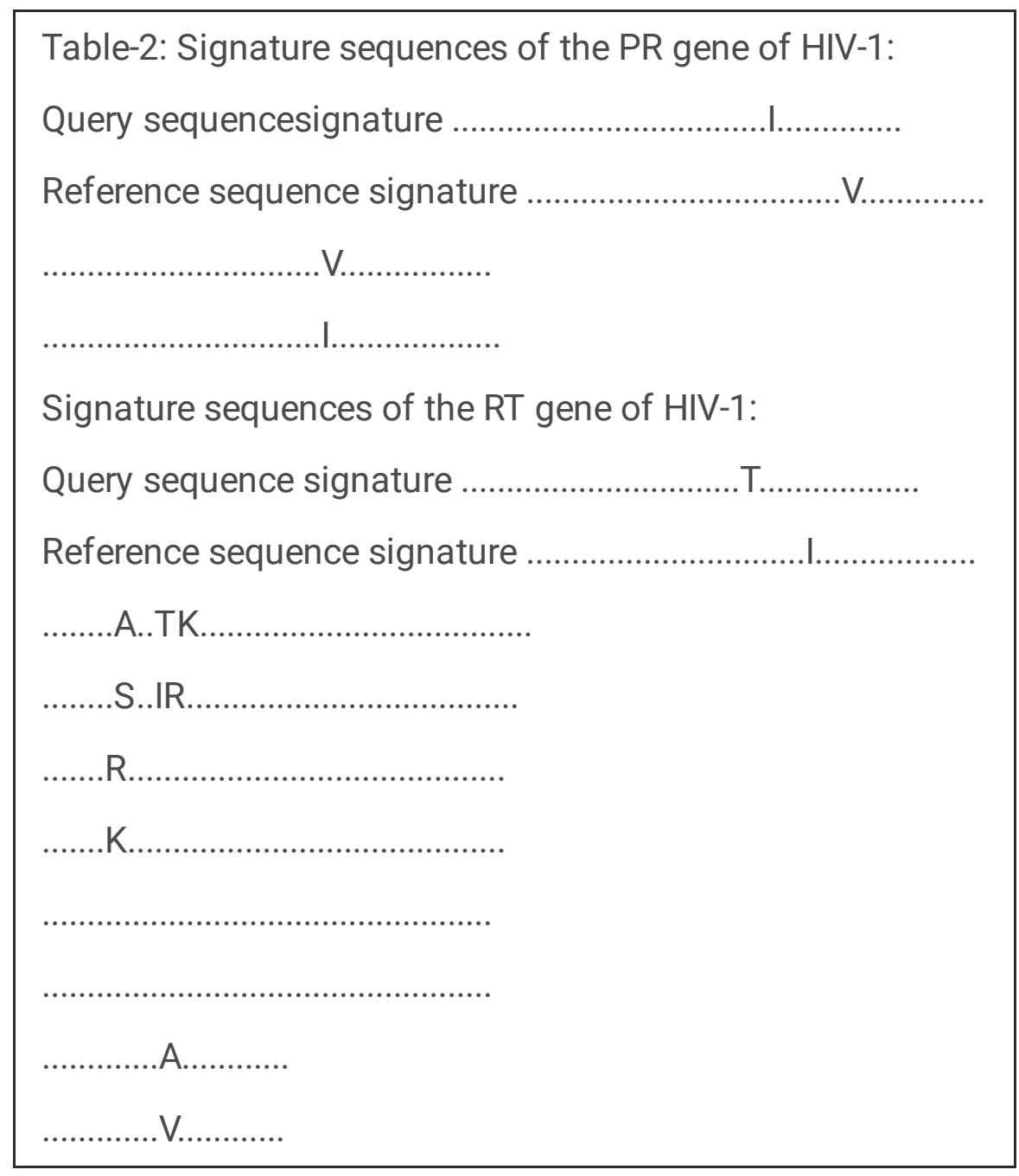

The signature amino acids of the protease gene were found with the reference background sequences at frequencies of 0.57 to 0.85 . The signature amino acids of the reverse transcriptase gene were found with the reference background sequences at frequencies 0.44 to 1.0 . The signature frequency of protease and reverse transcriptase gene are given in the Table-3 and Table-4. 
Table 3

Signature amino acid frequencies of protease gene:

\begin{tabular}{|lll|}
\hline Query signature amino acids & I & V \\
\hline Frequency among the query set & 0.571 & 0.857 \\
\hline Frequency among the background set & 0.000 & 0.000 \\
\hline Background amino acids & $\mathbf{V}$ & $\mathbf{I}$ \\
\hline Frequency among the query set & 0.000 & 0.000 \\
\hline Frequency among the background set & 1.000 & 1.000 \\
\hline Alignment position & 36 & $\mathbf{8 2}$ \\
\hline
\end{tabular}

Table 4

-Signature amino acid frequencies of reverse transcriptase gene:

\begin{tabular}{|lllllll|}
\hline Query signature amino acids & $\mathbf{T}$ & $\mathbf{A}$ & $\mathbf{T}$ & $\mathbf{K}$ & $\mathbf{R}$ & $\mathbf{A}$ \\
\hline Frequency among the query set & 0.444 & 0.444 & 1.000 & 0.778 & 0.667 & 0.667 \\
\hline Frequency among the background set & 0.000 & 0.000 & 0.000 & 0.000 & 0.000 & 0.000 \\
\hline Background amino acids & $\mathrm{I}$ & $\mathbf{S}$ & $\mathrm{I}$ & $\mathbf{R}$ & $\mathbf{K}$ & $\mathbf{V}$ \\
\hline Frequency among the query set & 0.333 & 0.222 & 0.000 & 0.222 & 0.333 & 0.222 \\
\hline Frequency among the background set & 1.000 & 1.000 & 1.000 & 1.000 & 1.000 & 1.000 \\
\hline Alignment position & $\mathbf{3 2}$ & $\mathbf{5 9}$ & $\mathbf{6 2}$ & $\mathbf{6 3}$ & $\mathbf{1 0 8}$ & $\mathbf{2 1 4}$ \\
\hline
\end{tabular}

The selection pressure acting on the $P R$ gene and the $R T$ gene of archived DNA was evaluated at the coding level by subjecting the all $P R$ gene $R T$ gene sequences of clinical isolates along with the Indian subtype $C$ reference (AB023804). The $d s / d n$ ratio of $P R$ gene $(d s=0.08, d n=0.02, d s / d n=5.02)$ and $R T$ gene were $(\mathrm{ds}=0.16, \mathrm{dn}=0.02, \mathrm{ds} / \mathrm{dn}=6.31$ ) calculated. Hypermutated proviral sequences were analysed through the identification of an excessive $\mathrm{G} \rightarrow \mathrm{A}$ change pattern consistent with APOBEC3G/F signature. The $9 R T$ and $7 P R$ archived DNA sequences were compared to a reference sequence, tallies $\mathrm{G}$ to $\mathrm{A}$ hypermutation. The nine patients had no $\mathrm{G}$ to A potential mutations in the $P R$ and $R T$ genes of HIV-1. Shannon entropy has been defined in terms of the probabilities of the different sequences or clusters of sequences that can present at a given time point. To evaluate the genomic stability of protease and reverse transcriptase gene of archived DNA of $>1$ to $<7$ years of ART, the Shannon entropy analysis of each amino acid codon was performed. The 63 positions of amino acid $P$ were observed as the highest random entropy $=1.352$ in the protease gene of archived DNA. The amino acid T, A at position 32 and 59 was observed as the highest random entropy $=1.369$ in the reverse transcriptase gene of archived DNA. The entropy differences between the two sets were observed in $<=5$ of the 100 randomizations.

\section{Discussion}


The human immunodeficiency virus evolves rapidly. The diversity of the HIV genome is a major factor due to error-prone reverse transcription, recombination, etc. Diversity trends lead to the failure of the immune system [13]. To see the diversity of the HIV-1, the pattern of amino acids of the protease and reverse transcriptase gene has been characterized through the VESPA method as it is associated with drug resistance towards first-line antiretroviral therapy. Genotyping in proviral DNA was reported earlier [4]. The primers of WHO dried blood spot protocol 2010 was used for analysis of drug resistance mutations in low level RNA copies patients ( $\leq 40$ copies $/ \mathrm{ml}$ ). Thus, this protocol is useful for genotyping study from archived DNA samples. The patients with drug resistance mutations during low-level viremia were associated with a higher risk of therapy failure [14]. In our study, out of nine patients, two patients have NRTI and NNRTI associated drug resistance mutations M184V, M184I and Y181C, H221Y, M230I. The two patients are at a higher risk of therapy failure. Characterization of $H I V-1$ proviral DNA would be helpful in the monitoring of $H I V$ drug resistance variants clinical impact of regimens and treatment success [3]. Characterization of the proviral genome was indicated to have significance in monitoring HIV minority drug resistant variants in Brazil [3]. Although our samples are limited to nine numbers, genotyping test may be giving valuable information which would be helpful for HIV drug resistant variants in the region of the northern part of India. The proviral DNA sequencing provides additional information on drug resistance mutation that impacts on treatment decision and transmission dynamics in a community program [4]. Our findings of the proviral DNA testing of nine long term ART users ( $>1$ to < 7 years) may have some impact on treatment decision and transmission dynamics. The study of the nucleotide substitution is very important to understand the evolutionary features of the virus and its biological implications [15]. For this reason, our data on the nucleotide substitution ratio (Synonymous to non - synonymous) of $P R$ and $R T$ gene of archived DNA would be important in evolutionary studies. Apolipoprotein B mRNA editing catalytic polypeptide like 3 (APOBEC3 (A3)) protein played an important role in the HIV-1 evolution and drug resistance [16]. In our study findings, the nine patients had no $G$ to $A$ mutations. This could be due to the blocking of Vif by the A3 genes in the host. The patients were immunologically tolerable to HIV-1 infection. These nine proviral DNA could be useful in new drug design as all the sequences may be useful in the design of the model to prevent APOBEC3 degradation.

\section{Conclusion}

The analysis of the drug resistance mutation in the protease and reverse transcriptase gene of the archived DNA of HIV- 1 subtype $C$ infected patients over 1 to $=<7$ years of first-line ART may be helpful in the treatment guideline. A few signature amino acids were persisted in the reverse transcriptase and protease gene of similar HIV- 1 subtype $C$ infected patients over 1 to $=<7$ years of first line ART in comparison to the reference sequence. This archived DNA drug resistance mutation testing could be an important tool when RNA testing becomes unsuccessful.

\section{Abbreviations}

HIV 
Human Immuno-deficiency virus

AIDS

Acquired immune-deficiency syndrome

DNA

Deoxyribonucleic acid

PR

Protease

RT

Reverse transcriptase

VESPA

Viral Epidemiology Signature Pattern Analysis

APOBEC 3(A3)

Apolipoprotein B mRNA editing catalytic polypeptide like 3 (APOBEC3 (A3))

\section{Declarations}

\section{Competing interest}

“No competing financial interests exist."

\section{Funding}

Indian Council of Medical Research, Govt. of India has funded the senior research fellowship of Sushanta Kumar Barik and contingencies grant. The sanction file number of the project: 80/990/2015ECD-I.

\section{Ethics committee}

The name of ethics committee: Human Ethics committee, Registration Number-ECR/257/Inst/UP/2013, situated at National JALMA Institute for Leprosy and Other Mycobacterial Diseases, Agra (Indian Council of Medical Research), Taj Ganj, Agra-282004. The ethics committee meeting was held on 27.5.2016 for the project "Characterization of drug resistant HIV-1 mutants of Agra region, India by genomic and proteomic approaches.

Ethics Approval and Consent to Participate: The details of the research plan of the study were informed to the patients in Hindi language in written form. Then the written informed consent was obtained from the study participants. This study was approved by the ethics committee.

\section{Consent for publication}


All authors have assigned this article for publication to this journal.

Availability of data and materials: Yes, PR and RT gene sequences at NCBI

\section{Authors's Contributions}

Mr Sushanta Kumar Barik, National JALMA Institute for Leprosy and Other Mycobacterial Diseases, TajGanj, Agra: Project and paper writing, Sample collection, viral load, genotyping and analysis of HIVDR data.

Dr Partha Sarathi Mohanty: Reviewed the manuscript.

Dr Srikanth Prasad Tripathy, National Institute for Research in Tuberculosis, Chetpet, Chennai: Conceptualized this research proposal on the first line ART patients in Agra region, India.

Ramesh Karunaianantham, National Institute for Research in Tuberculosis, Chetpet, Chennai:

Experiments on Genotyping of HIVDR samples and analysis.

Luke Elizabeth Hanna, National Institute for Research in Tuberculosis, Chetpet, Chennai: Reviewed the manuscript of the first line ART patients.

Prof. Tejpal Singh, Sarojini Naidu Medical College, Agra: Supervision of the patients attending the S.N. Medical College, Agra.

Dr Rekha Tandon, Sarojini Naidu Medical College, Agra: Evaluation and supervision of the patients attending the S.N. Medical College, Agra.

Dr Srikant Jena, Ravenshaw University, Cuttack: Reviewed the manuscript.

Dr Keshar Kunja Mohanty, National JALMA Institute for Leprosy and Other Mycobacterial Diseases, Tajganj, Agra: Reviewed, editing the proposal, supervision of laboratory work, supervision of data analysis, reviewing and editing manuscript.

\section{References}

1. Seth P. Evolution of HIV-1 in India. InNature at Work: Ongoing Saga of Evolution 2010 (pp. 93-101). Springer, New Delhi.

2. Wensing AM, Calvez V, Günthard HF, Johnson VA, Paredes R, Pillay D, Shafer RW, Richman DD. 2017 update of the drug resistance mutations in HIV-1. Topics in antiviral medicine. 2016 Dec;24(4):132.

3. Alves BM, Siqueira JD, Garrido MM, Botelho OM, Prellwitz IM, Ribeiro SR, Soares EA, Soares MA. Characterization of HIV-1 near full-length proviral genome quasispecies from patients with undetectable viral load undergoing first-line haart therapy. Viruses. 2017 Dec;9(12):392. 
4. Derache A, Shin HS, Balamane M, White E, Israelski D, Klausner JD, Freeman AH, Katzenstein D. HIV drug resistance mutations in proviral DNA from a community treatment program. PLoS One. 2015;10(1).

5. Lübke N, Di Cristanziano V, Sierra S, Knops E, Schülter E, Jensen B, Oette M, Lengauer T, Kaiser R. Resina Study Group. Proviral DNA as a target for HIV-1 resistance analysis. Intervirology. 2015;58(3):184-9.

6. Korber B, WOLINSKY S, Haynes B, Kunstman K, Levy R, Furtado M, Otto P, Myers G. HIV-1 intrapatient sequence diversity in the immunogenic V3 region. AIDS research and human retroviruses. 1992 Aug;8(8):1461-5.

7. Harris RS, Liddament MT. Retroviral restriction by APOBEC proteins. Nature Reviews Immunology. 2004 Nov;4(11):868-77.

8. Hu Y, Tan PT, Tan TW, August JT, Khan AM. Dissecting the dynamics of HIV-1 protein sequence diversity. PLoS One. 2013;8(4).

9. Barik SK, Tomar S, Tandon R, Mohanty KK, Joshi B. Practical Challenges in Implementing a Simplified Leaflet for HIV Patients in Resource Poor Settings: The Practice towards Public Health. J Gen Pract. 2018;6(347):2.

10. Indian Council of Medical Research. Ethical guidelines for biomedical research on human participants. Ethical Review Procedures. 2006.

11. World Health Organization. WHO manual for HIV drug resistance testing using dried blood spot specimens, March, 2010.

12. Mochizuki N, Otsuka N, Matsuo K, Shiino T, Kojima A, Kurata T, Sakai K, Yamamoto N, Isomura S, Dhole TN, Takebe Y. An infectious DNA clone of HIV type 1 subtype C. AIDS research and human retroviruses. 1999 Sep 20;15(14):1321-4.

13. Van Loon K, van Zaane B, Bosch EJ, Kalkman CJ, Peelen LM. Non-invasive continuous respiratory monitoring on general hospital wards: a systematic review. PLoS One. 2015;10(12).

14. Swenson LC, Min JE, Woods CK, Cai E, Li JZ, Montaner JS, Harrigan PR, Gonzalez-Serna A. HIV drug resistance detected during low-level viremia is associated with subsequent virologic failure. AIDS (London, England). 2014 May 15;28(8):1125.

15. Suzuki Y, Yamaguchi-Kabata Y, Gojobori T. Nucleotide substitution rates of HIV-1. AIDS Rev. 2000;2(1):39-47.

16. Jern P, Russell RA, Pathak VK, Coffin JM. Likely role of APOBEC3G-mediated G-to-A mutations in HIV1 evolution and drug resistance. PLoS pathogens. 2009 Apr;5(4).

\section{Supplementary Files}

This is a list of supplementary files associated with this preprint. Click to download.

- SupplementaryfilesofarchivesDNAsamplesequences.txt 
- Supplementarytablesforprimersandpcrconditions.docx 